\title{
O Brasil é um Estado Racista? \\ Dois ou três apontamentos e algumas definições.
}

\section{A perda do mundo comum: figurações do racismo de Estado.}

Em Homo Sacer, Giorgio Agamben identifica o campo de concentração como regra, generalização, constituindo o grande "paradigma biopolítico do Ocidente" (Pelbart, 2003, p. 95). Agamben utiliza como exemplo desse fato as "cobaias humanas" (Versuchepersonen) usadas em experiências científicas do regime nazista, mas questiona o uso das "cobaias humanas" em larga escala no século XX, em especial nos Estados Unidos:

Se, era de fato teoricamente compreensível que semelhantes experimentos não tivessem suscitado problemas éticos em pesquisadores e funcionários no interior de um regime totalitário, o qual se movia num horizonte declaradamente biopolítico, como era possível que experimentos em certa medida análogos pudessem ter sido conduzidos em um país democrático? (Agamben, 2007, p. 165-166)

\footnotetext{
${ }^{1}$ Professor do Instituto Federal de Goiás - Campus Formosa. Doutorando em História na Universidade Federal de Goiás.

${ }^{2}$ Professor da Universidade Estadual de Goiás - Unidade de Goiás. Doutorando em História na Universidade Federal de Goiás.
}

Brasiliana - Journal for Brazilian Studies. Vol. 3, n.1 (Jul. 2014). ISSN 2245-4373. 
O que se evidencia é a introdução no corpo institucional-político ocidental de certa racionalização da violência, uma absorção por parte das democracias e não apenas dos regimes totalitários, da violência e seus usos, fato que Agamben considerou "politizar a morte".3

$\mathrm{Na}$ contemporaneidade a violência cada vez mais se estabelece como uma constante. É uma invasão de nossas vidas e de nosso dia a dia. Figuram nas ciências humanas, em geral, uma série de estudos em torno do crime e da criminalidade em seu caráter de elemento social inerente às relações entre os homens ${ }^{4}$. No entanto é irônico que, ao percorrermos um catálogo de biblioteca, encontremos poucos trabalhos que se dedicam a pensar e discutir a violência, enquanto fenômeno historicamente efetivado. Segundo Hannah Arendt (2000, p. 16):

Ninguém que se tenha dedicado a pensar a história e a política pode permanecer alheio ao enorme papel que a violência sempre desempenhou nos negócios humanos, e, à primeira vista, é surpreendente que a violência tenha sido raramente escolhida como objeto de consideração especial.

\footnotetext{
$3 \mathrm{O}$ autor se refere também às discussões em torno do coma e da intervenção do Estado gerenciando a vida do limiar ao fim. "Os organismos pertencem ao poder público: nacionaliza-se o corpo. Nem Reiter nem Verschuer tinham jamais avançado tanto no caminho da politização da vida nua; mas (sinal evidente que a biopolítica ultrapassou um novo umbral) nas democracias modernas é possível dizer publicamente o que os biopolíticos nazistas não ousavam dizer."

4 Cf: Bicudo, Hélio. Violência: o Brasil cruel e sem maquiagem. São Paulo: Moderna, 1994; Cancelli, Elizabeth. A cultura do crime e da lei (1889-1930). Brasília: Ed. Da Universidade de Brasília, 2001; Corrêa, Mariza. Morte em família: representações jurídicas de papéis sexuais. Rio de Janeiro: Edições Graal, 1983; Os crimes $d a$ paixão. São Paulo: Brasiliense, 1981; Fausto, Boris. Crime e cotidiano: a criminalidade em São Paulo (1880-1924). São Paulo: Brasiliense, 1984; Martins, José de Souza. As condições do estudo sociológico dos linchamentos no Brasil. Estudos Avançados, vol.9, n²5, São Paulo, 1995. Disponível em: http://www.scielo.br/scielo.php?script=sci_arttext\&pid=S0103-40141995000300022, acessado em 24/03/06. Veja-se ainda o importante Núcleo de Estudos da Violência (NEV) da Universidade de São Paulo (USP): http://www.nevusp.org/
}

Brasiliana - Journal for Brazilian Studies. Vol. 3, n.1 (Jul. 2014). ISSN 2245-4373. 
Assim, para Arendt “[...] isso indica o quanto a violência e sua arbitrariedade foram consideradas corriqueiras e, portanto, desconsideradas", com a consequência de que "[...] quem quer que tenha procurado alguma forma de sentido nos registros do passado viu-se quase que obrigado a enxergar a violência como um fenômeno marginal" (Arendt, 2000, p. 16).

A crítica de Arendt se refere ao fato de que toda uma tradição de pensamento acabou por glorificar e, em muitos casos, legitimar a instrumentalização política da violência. Essa crítica encontra ressonância no contexto em que sua obra se insere paralelamente ao problema sob o qual o autora pensa: o contexto histórico do final dos anos 60 e também do século XX, de um modo geral. Torna-se inegável o fato de que a guerra e a revolução não são as únicas formas de interrupção do processo histórico. Todavia, pela perspectiva de Hannah Arendt, toda ação tem função de irromper o que teria acontecido automaticamente.

Desse modo, Arendt procura perceber, de modo diacrônico, a defasagem no pensamento de toda uma tradição intelectual que não possui ferramentas suficientes e satisfatórias para lidar com as experiências totalitárias e com o lugar da violência na cultura ocidental do século XX. A crítica maior reside no fato de que a violência "se naturalizou" nas sociedades contemporâneas, tornando-se de certo modo onipresente. Na perspectiva de Jean Baudrillard (1990, p. 89):

Numa sociedade em que, à força de profilaxia, de extinção das referencias naturais, de embranquecimento da violência, de exterminação dos germes e de todas as partes malditas, de cirurgia estética do negativo, só se quer tratar com a gestão calculada e com o 
discurso do Bem, numa sociedade em que já não há possibilidade de enunciar o Mal, este metamorfoseou-se em todas as formas virais e terroristas que nos obsessionam.

Para Arendt (2000), a violência não é e não deve ser glorificada pois suas consequências são terrificantes. A própria legitimação da violência, seja na forma do "olho por olho" (daí a emergência dos atos de vingança e justiçamentos), seja na defesa do endurecimento dos instrumentos estatais de repressão, o que apenas dificulta a superação da "banalidade do mal" no presente. Em Eichmann em Jerusalém, Arendt desloca a questão do mal e da ação humana para um outro nível.

É nesse emaranhado de causas e sentimentos, atos e efeitos, que podemos compreender o lugar da violência no cotidiano e nas vidas dos homens (especialmente dos séculos XX e XXI), regidas sob as insígnias da malsã e da imprevisibilidade constante diante da eminência dos atos violentos. Na observação do sociólogo Zigmunt Bauman (2001, p. 12), as lutas culturais contemporâneas são profundamente marcadas por essa ambivalência, essa luta constante entre caos e ordem, o que é próprio da modernidade e de seu projeto.

Essa argumentação "permite melhor compreender as sociedades passadas nas relações que mantém com o sangue, a dor, o combate, as rixas, os conflitos", ao mesmo tempo em que torna possível a análise de formas sutis que salientam aspectos das sociedades e repousam sobre o crime, o conflito, a crise, "com tudo que isso provoca de horror, com tudo o que isso faz nascer de solidariedades e contra-solidariedades" (Farge, 1993, p. 771), pois a violência é capaz de catalisar a seu redor diversas manifestações de sensibilidades coletivas, emoções capazes de motivar atitudes extremas em nome de seus próprios sentimentos.

Brasiliana - Journal for Brazilian Studies. Vol. 3, n.1 (Jul. 2014). ISSN 2245-4373. 
Hannah Arendt (2000, p. 41) contesta o que denomina "equação ordinária": “[...] violência e poder assenta-se na compreensão do governo como a dominação do homem pelo homem através da violência." A violência só tem sentido quando é "re-ação" e tem medida, como os casos de legítima defesa. Ela perde sua razão de ser quando se transforma numa estratégia, ou seja, quando se racionaliza, instrumentaliza e se converte em princípio e não fim de ação, como ocorreu nos sistemas totalitários e em vários regimes ditatoriais pelo mundo no século $\mathrm{XX}$.

Daí emerge a critica arendtiana ao pensamento vitalista, que relaciona violência, vida e criatividade (Bergson, Nietzsche, Sorel) como complementares e funcionais entre si. Para além das derivações do comportamento humano de outras espécies animais, Hannah Arendt ressalta que a violência não é bestial nem irracional: é força incontrolável e inerente a todos os homens, mesmo quando motivada por sentimentos tidos como irracionais. "É como se tivéssemos caído sob o encantamento de uma terra de fadas que nos permite realizar façanhas fantasticamente extraordinárias, sob a condição de realizarmos o impossível mas não o possível, de não resolvermos nossas questões cotidianas" (Arendt, 1997, p. 122).

Todos esses desenvolvimentos podem nos conduzir à diminuição do poder e à sua substituição pela violência, o que se que se tornou uma constante no século XX. E aí adentramos nos estudos de Hannah Arendt sobre o totalitarismo:

Em meus estudos sobre o totalitarismo tentei mostrar que o fenômeno totalitário, com seus berrantes traços antiutilitários e seu estranho menosprezo pela frustração pela fatualidade, se baseia, em ultima análise, na convicção de que tudo é possível, e não apenas permitido, 
moralmente ou de outra forma, como o niilismo primitivo. (Arendt, 1997, p. 123)

Essa noção se encaixa na necessidade de Arendt de compreender um fenômeno sem par na história humana, o qual guarda em si a terrível constatação do esvaziamento completo do sentido da vida entre os homens, que foi o totalitarismo, "pois uma sociedade de massas nada mais é que aquele tipo de vida organizada que automaticamente se estabelece entre seres humanos que se relacionam ainda uns aos outros mas que perderam o mundo outrora comum a todos eles" (Arendt, 1997, p. 126).

Como construir relações interpessoais, comunitárias ou nacionais pautadas no diálogo e na reflexão? Tal questão guarda em si uma postura ética. No entanto, os horrores e mazelas dos séculos XX e XXI - descolonização, conflito árabe-israelense, guerras do Iraque e do Afeganistão, atentados terroristas locais como ações do ETA, IRA, ou de grande repercussão como o atentado ao World Trade Center, em 11 de setembro de 2001 - constituem um grande retorno às práticas de violência que a sociedade contemporânea teria eliminado do espaço público desde a Revolução Francesa. Para Baudrillard: “[...] nossa violência produzida por nossa hipermodernidade, é o terror." (1990, p. 83).

Segundo Michel Onfray o suposto contrato social é uma falsa premissa no presente, mais uma crença que uma condição existente na relação governo-indivíduosociedade:

[...] passar, pelo contrato, do estado de natureza selvagem e sem lei, violento e perigoso, a um estado de cultura onde reinariam equilíbrio, harmonia, paz, comunidade pacífica é ridículo. O contrato social é o ato 
de batismo do religioso em suas formas sociais. Ele é hipoteticamente firmado, um dia, entre o individuo e a sociedade, depois esfola quase totalmente o primeiro em nome do segundo [...] Ele fabrica um homem calculável em suas escolas, onde se destrói sua inteligência em beneficio da docilidade. [...] Aceitar o contrato é receber as servidão e a escravidão, quando nos prometia a dignidade e a liberdade. (Onfray, 1995, p. 42)

Na sociedade de hoje a constituição do capitalismo global é um elemento unificador do modo de dominação. Mais do que nunca vivemos o tempo do império do qual nos falam Michael Hardt e Toni Negri (2001). Trata-se do império sem fronteiras, que se movimenta mediante uma padronização da cultura por seu esmigalhamento e pela desterritorialização e descentralização de seus componentes: fluxos de diversas ordens circulam por todo o império (pessoas, capital, imagens, propagandas, informações).

Podemos dizer também que o império contemporâneo mantém um modus operandi diferente daquele dos impérios coloniais do limiar da modernidade (séc. XVI) e de sua versão pós revolução industrial (séc. XIX). Vejamos algumas características dessa distinção ao mesmo tempo em que atentamos para as semelhanças.

\section{Encobrimento do outro e colonialidade: modernidade e violência}

Vejamos a questão das violências cometidas no alvorecer da modernidade. Não podemos esquecer que o movimento de expansão colonial da Europa, com a "descoberta" da América e suas posteriores conquista e colonização, contém em si violências físicas, morais, espirituais e epistemológicas. Ou seja, diferente do que 
comumente se pensa, as violências de nossa sociedade não são um elemento prémoderno que insiste em permanecer. Antes, são um elemento constitutivo da modernidade. Enrique Dussel (2008, p. 176) afirma o seguinte:

La perenne pregunta ante la Modernidad será: ¿Qué derecho tiene Europa de dominar colonialmente a las Indias? Una vez resuelto el tema (que filosóficamente refuta convincentemente Las Casas, pero que fracasa rotundamente en la praxis colonial moderna de las monarquías absolutas y del sistema capitalista como sistema-mundo) la Modernidad nunca más se preguntará existencial ni filosóficamente por este derecho a la dominación de la periferia hasta el presente. Ese derecho a la dominación se impondrá como la naturaleza de las cosas y estará debajo de toda la filosofía moderna.

Ou seja, seguindo esse raciocínio podemos concluir que a própria filosofia ocidental se baseia numa internalização da violência colonial. O direito autoconcedido pelos europeus $^{5}$ de conquistarem o mundo, de imporem as suas formas de organização, parte da conclusão de que são superiores aos demais povos. É de fato um raciocínio circular: os outros são vistos como inferiores apenas por serem outros (Dussel, 1994).

Quando os europeus se põe a discutir se os índios são seres humanos como eles ou se são inferiores - por exemplo, na controvérsia de Valladolid entre Las Casas e Sepúlveda - podemos enxergar também que há um elemento racial no debate. Os índios são vistos como outro tipo de pessoas, mesmo sendo considerados humanos.

5 Na visão de Dussel a Europa moderna começa com Portugal e Espanha, mas depois o eixo de poder se desloca para França, Alemanha, Inglaterra e Holanda, com os ibéricos passando a um segundo plano, chegando a serem considerados uma sub-Europa. 
A crítica que se faz às violências coloniais não pode ser vista como anacrônica. Pensadores como Bartolomé de Las Casas, já citado, Vasco de Quiroga e Felipe Guaman Poma de Ayala fizeram já naquele momento a crítica da violência. Dussel resgata Guaman Poma de Ayala, um descendente dos incas, para mostrar que os europeus eram criticados usando seus próprios códigos:

Es decir, Guamán demostrará con razones la contradicción en la que vive la Modernidad. Se critica entonces la praxis de dominación de los mismos cristianos españoles partiendo de su propio texto sagrado: la Biblia. Es una argumentación cerrada que muestra la contradicción performativa de la Modernidad en su totalidad. Queremos dejar claro, entonces, que Felipe Guamán distingue entre la creencia que pudiéramos llamar teórica (o «cosmovisión») y la práctica o ética propiamente dicha. En tiempo de los Incas, éstos «idolatraron» en su cosmovisión (desde la dogmática cristiana), pero «guardaron los mandamientos» en su comportamiento ético, «lo qual no guarda agora los cristianos» europeos. Es decir, los indígenas fueron, prácticamente, aún antes de la conquista, mejores «cristianos», por sus prácticas, que los cristianos españoles de «agora». (Dussel, 2008, p. 171)

Aqui aparece como próprio dos europeus fazer uma separação entre suas construções teóricas e a vivência prática, dando maior relevância para a teoria. Para resgatar a argumentação de Arendt, aqui não temos um poder legítimo, mas uma dominação imposta unicamente pela violência injustificada e que, de acordo com Dussel, contraria a própria moral dos que a cometiam. 
Talvez seja justamente essa separação entre a teoria e a prática que permita os homens realizarem grandes façanhas técnicas sem que possa resolver seus problemas sociais. Enxergando a violência como constitutiva da modernidade podemos entender também como os próprios colonizadores acabam se voltando uns contra os outros em diversas guerras, sobretudo nos dois grandes conflitos do século XX. A violência interna àquelas sociedades acaba por ultrapassar a barreira da relação colonizador-colonizado. E de fato, além das, guerras, podemos ver os próprios povos colonizadores sofrendo com isso - daí a relevância dos estudos de Arendt.

No entanto, ao contrário do que pensam Hardt e Negri, o Império sem fronteiras não acaba com a colonialidade. Santiago Castro-Gómez (2005, p. 71-72) escreve o seguinte:

Quiero proponer una crítica de H\&N que rescate algunos elementos de su teoría del capitalismo posmoderno pero que, al mismo tiempo, señale sus deficiencias sobre el diagnóstico del colonialismo. Formulada en términos positivos mi tesis será que el concepto de Imperio permite avanzar un análisis crítico del capitalismo global que suplementa y, en algunos casos, reemplaza el diagnóstico realizado con el concepto de imperialismo. Hay reglas y actores imperiales que siguen siendo los mismos que fueron pensados con el concepto de imperialismo; en esto tienen razón los numerosos críticos del libro. Pero han surgido otras reglas y otros actores globales que el campo de visibilidad abierto por el concepto de imperialismo no permite ver y que se están tornando hegemónicos en la economía posfordista; en este aspecto el concepto de Imperio revela su importancia. Formulada en términos negativos mi 
tesis será que la genealogía del Imperio, tal como es reconstruida por $H \& N$, dificulta el entendimiento de fenómenos típicamente modernos que persisten en él, como el occidentalismo, las jerarquías epistémicas y el racismo. Desde mi punto de vista la genealogía del Imperio que proponen H\&N es incompleta y debería ser complementada con lo que aquí denomino el «capítulo faltante de Imperio».

A crítica de Castro-Gómez pode ser entendida através de muitos exemplos que vivemos no cotidiano. Os padrões de beleza, as roupas, a música e diversos outros elementos mantém um padrão europeu ou estadunidense - de qualquer forma, ocidental. A questão fundamental é que a pós-modernidade não elimina completamente a colonialidade moderna. De acordo com Castro-Gómez (2005, p. 74) - evocando Walter Mignolo - "así como la colonialidad es la «otra cara» constitutiva de la modernidad la poscolonialidad es la contrapartida estructural de la posmodernidad". O sentido dessa afirmação é que com relação ao padrão colonial de dominação, de exercício de poder, não há uma ruptura entre modernidade e pós-modernidade, mesmo que se reconheça essa divisão como verdadeira. Assim, ainda que estejamos distantes temporalmente do início da colonização, não o estamos no que concerne ao eurocentrismo e ao racismo. Este último tem recrudescido de forma preocupante, com diversas manifestações explícitas por exemplo, vejam-se os diversos casos recentes de injúrias raciais nos estádios de futebol ou de piadas racistas em programas de televisão - que na maioria das vezes resultam apenas em pequenas sanções ou mesmo impunidade total.

Há ainda um exemplo importante fornecido por Juan Camilo Cajigas-Rotundo (2007, p. 178) quando trata do que denomina biocolonialidade do poder. Falando sobre 
as relações entre os conhecimentos tradicionais de vários povos e os registros de patentes, ele nos fornece um dado impressionante:

Hasta el momento, el $93 \%$ de las patentes ha sido otorgado a Estados Unidos, la Unión Europea o Japón, y tan sólo el 3\% ha sido concedido a "países en desarrollo" (Hernández, 1999). Es evidente la tendencia hacia la concentración global del poder y del conocimiento, y hacia el establecimiento de nuevas formas (posmodernas) de colonialidad.

Ou seja, nesse caso o poder não está desterritorializado e descentralizado, como querem Hardt e Negri, mas localizado e com fronteiras. Isso explicita também a persistência da violência colonial contra os povos não ocidentais. Cajigas-Rotundo (2005, p. 178) diz ainda o seguinte:

Los tratados imperiales sobre biodiversidad y propiedad intelectual privilegian una noción cientificista/empresarial del saber, esto es, individual, fragmentaria, compartimentalizada, cibernético-mecanicista y patriarcal. Esta formación del saber proyecta sobre la naturaleza un conjunto de campos analíticos sobre los cuales se levantan ciertos objetos de conocimiento, que aparecen como entidades aisladas entre sí, desconociendo sus interrelaciones (Capra, 2003). Así, la tecnociencia biopolítica constituye la vida orgánica como una máquina cibernética. Con todo, en estos tratados no se tiene en cuenta, de manera integral, el carácter colectivo de las formaciones de saber y sistemas de conocimiento propios de los pueblos no occidentales. Este tipo de 
saberes sólo son tenidos en cuenta en la medida en que sirven como catalizadores en las empresas de bioprospección y biopiratería, es decir, en la medida en que proveen de información sobre el uso y la ubicación de material biológico susceptible de comercialización.

É preciso reconhecer como válidos os modos não ocidentais de conhecimento e de relação com a natureza. Destaque-se que muitos povos não compartilham dessa distinção entre humanidade e natureza ou entre cultura e natureza. Ao aceitar essas outras formas de conhecimento estamos seguindo a trilha de Dussel, que procurou mostrar o encobrimento do outro que foi levado a cabo com a invenção da modernidade.

A tarefa de superar a violência e repensar o lugar da política no presente caberá não apenas a outras estratégias de ação e intervenção no espaço público e no espaço da intimidade, mas de uma aposta nas potencialidades de singularização que ultrapassem a dicotomia indivíduo-sociedade ou indivíduo-massa. É essencial também desvelar a persistência de formas coloniais de violência, para que seja possível superá-las. É preciso permitir que aflorem as muitas formas de conhecimento encobertas pela colonialidade. Deve-se apostar mais uma vez no caráter imutável da política, ou pelo menos em sua face digna, qual seja a capacidade dos homens de agir juntos e produzir o novo, de fazer nascerem "pequenos milagres", para usar uma das expressões preferidas de Hannah Arendt.

\section{Racismo de Estado no Brasil: um exagero teórico?}


Temos acompanhado recentemente discussões e impasses sobre a questão das terras indígenas em vários lugares do Brasil. Apesar de a Constituição Federal de 1988 garantir a posse e o usufruto exclusivo aos povos originários - sobrepondo inclusive esse direito ao de propriedade - são inúmeras as notícias sobre a permanência de ocupações de terras indígenas já reconhecidas pelo estado. Essas ocupações resultam invariavelmente em conflitos violentos pela posse da terra, pois de um lado os fazendeiros não querem abrir mão do que consideram suas posses, por outro os indígenas reivindicam a ocupação tradicional e o direito constitucional.

Em uma matéria veiculada no site da revista Carta Capital no dia 29 de agosto de 2012 lemos o seguinte:

Três meses depois da reunião entre representantes do governo federal e lideranças indígenas em busca de soluções para a pacificação da região sul do Mato Grosso do Sul, um grupo da comunidade Guarani Kaiowá foi novamente atacada [sic] a tiros por pessoas não identificadas. A suspeita dos indígenas é de que o ataque da terça-feira 29, assim como os de outras ocasiões, partiu de fazendeiros da região que tentam reaver a terra ocupada pela etnia. (Gonçalves, 2012).

Vemos aqui a reincidência de um fato corriqueiro: indígenas sendo atacados e até mesmo mortos por reocuparem seus territórios tradicionais. Sabemos que o conflito não é simples, mas muitas vezes é potencializado pela ausência do estado brasileiro, que não cumpre suas obrigações constitucionais. Essa ausência prolongada permite que a violência se propague sem controle, sendo que os indígenas são claramente a parte mais fraca. 
Na notícia veiculada, contudo, há um elemento novo: “De acordo com os indígenas, esse foi o primeiro ataque na presença de autoridades" (Gonçalves, 2012). Pode ser que a ausência prolongada do estado tenha produzido naquele local uma espécie de terra sem lei, onde manda o mais forte e as regras são ditadas pelos interesses dos grandes capitalistas. É claro que essa é uma explicação superficial e preliminar, mas que permite entrever outras questões: é possível que a ausência do estado seja proposital? Dito de outra forma, essa ausência do estado pode ser entendida como uma anuência para que os fazendeiros ajam com violência, livre e impunemente? Neste caso estaria o estado corroborando os interesses do capital, associado diretamente ao racismo contra os índios, adotando uma postura claramente racista e colonial? Procuraremos responder essas perguntas a seguir.

Retomamos aqui o argumento de Agamben sobre a violência e a politização da morte mencionados no princípio deste texto. No caso dos Guarani Kaiowá - e de muitos outros povos indígenas - não se trata de experiências científicas, mas é possível enxergar a racionalização da violência, uma vez que a expulsão e o extermínio servem muito bem aos interesses do grande capital e estão vinculados ao modelo de desenvolvimento adotado pelo estado brasileiro.

A partir disso podemos entender que o estado brasileiro adota uma estratégia de violência contra os povos indígenas ${ }^{6}$, como é notável na Portaria $n^{0} 303$ da Advocacia Geral da União (AGU), de 16 de julho de 2012, que no artigo V diz o seguinte:

o usufruto dos índios [sobre as terras indígenas] não se sobrepõe ao interesse da política de defesa nacional; a instalação de bases, unidades

6 Não só contra os povos indígenas, mas também contra os quilombolas, os extrativistas, os pequenos agricultores, etc. Os indígenas são destacados aqui pela temática do texto.

Brasiliana - Journal for Brazilian Studies. Vol. 3, n.1 (Jul. 2014). ISSN 2245-4373. 
e postos militares e demais intervenções militares, a expansão estratégica da malha viária, a exploração de alternativas energéticas de cunho estratégico e o resguardo das riquezas de cunho estratégico, a critério dos órgãos competentes (Ministério da Defesa e Conselho de Defesa Nacional), serão implementados independentemente de consulta às comunidades indígenas envolvidas ou à FUNAI. (Destaque nosso).

Temos aqui a racionalização e a instrumentalização legal da violência para atender os interesses dos grandes capitalistas, denominados ironicamente de "estratégicos" no texto. Contrariando tanto a Constituição Federal quanto a Convenção 169 da Organização Internacional do Trabalho, essa portaria explicita a linha de atuação do governo, sua violência injustificada e sua postura racista contra os povos indígenas, negando-lhes até mesmo o direito à fala. São tratados, como no início da colonização da América, como cidadãos de segunda classe, crianças ou mesmo sub-humanos. Da mesma forma que Agambem se surpreendeu com os experimentos feitos com humanos num regime democrático, é surpreendente que essa portaria não tenha sido publicada no período da ditadura, mas durante um governo democrático.

\section{Eurocentrismo, Colonialidade e Colonialismo Interno}

A partir dos exemplos dados podemos pensar que, no Brasil, tudo é permitido contra os povos indígenas. Se no mundo contemporâneo da sociedade de massas as pessoas perderam seu mundo comum, o que dizer dos povos indígenas, que desde a colonização tiveram o seu modo de viver alterado a revelia de sua vontade? 
Em seu texto intitulado Meditaciones anti-cartesianas Enrique Dussel (2008, p. 166) tece um crítica à pretensa superioridade europeia, afirmando que usavam um

argumento tautológico, porque parte de la superioridad de la propia cultura simplemente por ser la propia, se impondrá en toda la Modernidad. Se declara no- humano el contenido de otras culturas por ser diferentes a la propia, como cuando Aristóteles declaraba en la Política a los asiáticos y europeos como bárbaros porque «humanos» eran sólo «los vivientes que habitaban las ciudades [helénicas]».

Como já dissemos, o outro é considerado inferior pelo único motivo de não ser como eu. A partir da conquista tem início um mecanismo intelectual que pretende provar a centralidade europeia, primeiro em relação à América e depois frente a todo o mundo. Esse mecanismo de fato foi bem sucedido, mas permaneceu escondido por muito tempo. Dussel explora as vozes dissonantes de Bartolomé de Las Casas e de Guamán Poma de Ayala, ainda no alvorecer da Modernidade, para desvelar essa construção racista, mostrando que a inferioridade dos índios não era um consenso mesmo no início do século XVI7.

O discurso da superioridade europeia se impôs na prática, a despeito das disputas de Las Casas e outros, e das bulas papais atestando a humanidade dos índios e proibindo sua escravização. Por muito tempo os indígenas foram vistos como subhumanos, sub-trabalhadores, sub-cidadãos, visão que, de muitas formas, permanece até

7 É claro que há outros estudos que mostram isso, como os tantos escritos sobre Las Casas e outros cronistas. O raciocínio de Dussel é mais amplo e procura demonstrar que o surgimento da Modernidade se dá com a chegada dos europeus à América e sua posterior conquista. Tenta mostrar também que o racismo é um elemento constitutivo da Modernidade, e não algo que simplesmente ocorre dentro ou apesar dela.

Brasiliana - Journal for Brazilian Studies. Vol. 3, n.1 (Jul. 2014). ISSN 2245-4373. 
hoje como uma espécie de senso comum. Não é preciso evocar todas as tragédias coloniais para demonstrar isso: um breve olhar sobre os noticiários recentes a respeito dos povos indígenas dá conta de demonstrar essa permanência. Mais fácil ainda seria conversar com muitas pessoas, dos interiores ou das capitais, e perguntar-lhes que sabem sobre os índios, e logo viriam resposta como "são preguiçosos", "não podem ser responsabilizados por crimes", "são como crianças", etc. Ainda nas Meditaciones Dussel (2008, p. 157) afirma o seguinte:

Europa nunca fue centro de la historia mundial hasta finales del siglo XVIII (digamos hasta el 1800, hace sólo dos siglos). Será centro como efecto de la Revolución industrial. Pero gracias a un espejismo, como hemos dicho, se le aparece a los ojos obnubilados del eurocentrismo toda la historia mundial anterior (la posición de Max Weber) como teniendo a Europa como centro.

Essa visão, que se impõe ainda mais com o imperialismo do século XIX, fez com que a Europa se tornasse um padrão de desenvolvimento para o resto do mundo. Esse papel, no século XX, foi assumido pelos Estados Unidos, sem que houvesse qualquer mudança significativa na sua concepção.

A partir desse padrão foi feita uma releitura da história, de forma que a Europa passasse a ser o centro do mundo, constituindo-se uma linha temporal contínua estabelecendo uma ligação direta entre as grandes civilizações do passado e as potências atuais. Temos assim, por exemplo, a Alemanha se auto construindo como herdeira da tradição clássica, especialmente dos gregos, vistos como um ápice de civilização. Com isso se criou a ideia de um único modelo de desenvolvimento, que não era mais o 
antigo, dos gregos, mas sim o capitalismo moderno e industrial. Tudo o que fosse diferente disse seria subdesenvolvido ou, nas palavras politicamente corretas atuais, estaria em desenvolvimento.

É bastante interessante evocar as ponderações de Dussel (1994, p. 13) a respeito do termo desenvolvimentismo:

La palabra española "desarrollismo" 8 es intraducible al alemán o inglés. Su raíz (desarrollo: Entwicklung, development) no permite la construcción de derivado despectivo, negativo, excesivo; como por ejemplo para "ciencia": el "cientificismo (Scientifizismus)" o el “cientificista (scientifizist)". Debería ser algo así como "developmentism" (o "developmentalism"). Se trata de una posición ontológica por la que se piensa que el "desarrollo" (=desarrollismo) que siguió Europa deberá ser seguido unilinealmente por toda otra cultura. Por ello, la "falacia del desarrollo" (=falacia desarrollista) no es ya una categoría sociológica o económica, sino una categoría filosófica fundamental. Es el "movimiento necesario" del Ser, para Hegel; su "desarrollo" inevitable. El "eurocentrismo" cae en la "falacia desarrollista" - son dos aspectos de "lo Mismo". ${ }^{9}$

Vendo-se como modelos de desenvolvimento, era natural que esses povos não concebessem a ideia de desenvolvimentismo, já que sempre teriam sido o centro do mundo. Mesmo com seus modelos e sua economia em crise nós, latino-americanos,

8 Em português temos o bem conhecido vocábulo "desenvolvimentismo".

9 Essa explicação está na nota de rodapé número 1 da obra citada.

Brasiliana - Journal for Brazilian Studies. Vol. 3, n.1 (Jul. 2014). ISSN 2245-4373. 
custamos a abrir mão dessa falácia. Como dizia o jornalista uruguaio José Enrique Rodó no início o século XX, "temos nossa nortemania" (1991, p. 69). Por isso as palavras de Dussel são importantes, para que possamos enxergar, como pede o poeta Mario Benedetti, que "el sur también existe"10.

Anibal Quijano (2005, p. 111) contribui para essa discussão, trazendo um elemento caro aos historiadores: o tempo. Ele afirma que:

os europeus geraram uma nova perspectiva temporal da história e resituaram os povos colonizados, bem como a suas respectivas histórias e culturas, no passado de uma trajetória histórica cuja culminação era a Europa (Mignolo, 1995; Blaut, 1993; Lander, 1997). Porém, notavelmente, não numa mesma linha de continuidade com os europeus, mas em outra categoria naturalmente diferente. Os povos colonizados eram raças inferiores e - portanto - anteriores aos europeus

É desse novo ordenamento temporal que surge a concepção de "povos atrasados". Disso decorre também que os atrasados devam passar por uma etapa de desenvolvimento para alcançar o nível dos desenvolvidos, o que é justamente o cerne do conceito de desenvolvimentismo, que tantos frutos rendeu no pensamento latino-americano.

Há problemas nesse raciocínio: primeiro, são concepções não demonstradas, mas assumidas como verdadeiras e impostas através da violência da dominação colonial. Segundo, os próprios europeus reconheceram que em muitos aspectos diversos povos

10 É um poema transformado em canção por Joan Manuel Serrat. A letra está disponível no sítio do cantor: http://www.jmserrat.com/index.php/es/discografia/J/1-joan-manuel-serrat/26-el-sur-tambien-existe/277-el-surtambien-existe. Acesso em: 6 set. 2012.

Brasiliana - Journal for Brazilian Studies. Vol. 3, n.1 (Jul. 2014). ISSN 2245-4373. 
americanos lhes eram superiores ${ }^{11}$. Terceiro, há uma pergunta não respondida a respeito desse ordenamento temporal inventado: como é possível que povos que vivem num mesmo tempo estejam em tempos diferentes? Criou-se a simultaneidade assimultânea ou a sincronia dessincronizada? A própria dificuldade em formular essa questão atesta a fraqueza do conceito. A despeito disso, essa ideia se tornou predominante e influencia de forma determinante a mentalidade social e a constituição de políticas de estado.

Para além das questões lógicas ou filosóficas temos o problema de os países "em desenvolvimento" nunca alcançarem os países desenvolvidos, conseguindo quando muito tornarem-se um simulacro dos países ditos centrais. É importante ressaltar que essas noções, muito marcadas pelo pensamento econômico, extrapolam essa esfera, influenciando os padrões culturais, as identidades individuais e coletivas, enfim, toda a vida que se vê impregnada de colonialidade. Como explica Quijano (2005, p. 112):

O notável disso não é que os europeus se imaginaram e pensaram a si mesmos e ao restante da espécie desse modo - isso não é um privilégio dos europeus - mas o fato de que foram capazes de difundir e de estabelecer essa perspectiva histórica como hegemônica dentro do novo universo intersubjetivo do padrão mundial do poder

De fato é notável que povos tão diferentes aceitem a superioridade europeia e adotem quase sem questionamentos seu modelo de desenvolvimento, que perpetua um padrão de poder colonial. Não se trata de evocar o nacionalismo para criticar essas práticas, como fazem alguns, mas de reconhecer que os modelos importados e impostos aqui não

11 Diversos cronistas atestam isso, e podemos tomar como exemplo o próprio Cortez, que destruiu Tenochtitlán apesar de achá-la maravilhosa.

Brasiliana - Journal for Brazilian Studies. Vol. 3, n.1 (Jul. 2014). ISSN 2245-4373. 
nos servem. A questão é considerar a realidade local para desenvolver projetos de governo e políticas de estado. Nesse sentido, como deixa claro a Portaria $n^{\underline{o}} 303$ da AGU, os índios são postos novamente em último lugar.

Cabe aqui lembrar as formulações de Victor Leonardi, que vê a violência como um elemento constante na colonização, e não esporádico, como pode parecer a alguns. Se temos ainda que criticar o eurocentrismo presente em nossa sociedade, é importante compreender que para os povos indígenas o Estado e a sociedade brasileiros continuam sendo coloniais. Conforme afirma Leonardi (1996, p 41), "no século XIX a nação brasileira deixa de ser colônia de Portugal para se tornar, ela própria, colonialista em relação aos povos autóctones, cujas terras foram tomadas, pela força, por meio de métodos clássicos do colonialismo". Costumeiramente se adota a periodização da história do Brasil com as divisões colônia, império e república, mas da perspectiva dos índios o período colonial ainda não acabou.

Ainda segundo Leonardi (1996, p. 86), as visões coloniais consideram as minorias étnicas como sendo:

formadas por indivíduos aos quais não se reconhece sequer a qualidade de seres humanos. A xenofobia contida em pensamentos desse tipo revela traços mais ou menos acentuados de uma espécie de doença mental que os colonialistas de todas as épocas sempre possuíram: uma monótona repetição da negação do outro, uma estereotipia prolongada e idêntica que aprisiona as variadíssimas relações interétnicas surgidas ao longo da história, num enfadonho e rígido sistema fixo de clichês. 
De fato vemos serem repetidos os mesmos argumentos contra os povos indígenas, com generalizações como: “Índio é vagabundo!", “Índio tem privilégio do governo!” e, talvez o mais comum, “É muita terra pra pouco índio!”. Esses clichês, para usar o termo de Leonardi, são rígidos, uniformizadores e não abrem nenhum espaço para que se possa pensar a respeito das diferenças culturais, da diversidade de visões dos povos sobre os mais variados aspectos da vida humana. Não, o padrão adotado é sempre o da sociedade ocidental ${ }^{12}$, com suas ideias de desenvolvimento e progresso, tendo a geração de capital como objetivo central, sobretudo através da exploração da natureza vista unicamente como recurso.

\section{Brasil: Estado Colonial e Racista?}

Discutimos brevemente neste texto as ideias de Hannah Arendt sobre a violência, que é racionalizada e instrumentalizada quando o Estado se torna racista. Arendt, bem como Giorgio Agamben, estavam preocupados sobretudo com problemas da sociedade ocidental, como os campos de concentração nazistas e os experimentos científicos feitos em humanos nos Estados Unidos. Entendemos, porém, que suas formulações podem nos ajudar a pensar o caso do Brasil, especificamente as relações entre o estado e os povos indígenas. Partindo dos conceitos de Arendt, podemos entender que, quando o estado brasileiro usa - ou permite através da omissão - a violência contra os povos indígenas para defender interesses de grandes capitalistas, ele perde a sua legitimidade perante esses povos e se distancia da democracia, aproximando-se do totalitarismo no que concerne a negação do outro e sua necessária eliminação e anulação em sociedade.

12 A despeito de nós, latino-americanos, comumente pensarmos que fazemos parte da civilização ocidental, pensadores como Samuel Huntington, defensor da ideia do choque de civilizações, consideram que a América Latina é uma parte do mundo externa ao Ocidente, não sendo incluída mesmo entre as grandes civilizações. 
A partir das ideias de Enrique Dussel e Anibal Quijano entendemos que a Europa, através da violência, conseguiu se impor como centro do mundo, promovendo uma revisão da história e criando um padrão de desenvolvimento. Os países latinoamericanos, o Brasil incluso, aceitaram essas ideias e os estados foram organizados de forma que seguissem esse padrão, criando o conceito de desenvolvimentismo. Com Victor Leonardi entendemos que o Brasil foi, ao mesmo tempo, colonizado de colonizador. Se, por um lado, sofreu com o colonialismo e o imperialismo europeu - e, posteriormente, também estadunidense -, por outro foi colonial com relação aos povos indígenas e populações tradicionais (caboclos, ribeirinhos, sertanejos, dentre outros).

Os diversos saberes, práticas e organizações sociais dos povos indígenas foram sistematicamente excluídos ou silenciados. Contribuíram muito para a constituição do povo brasileiro, como bem atestam nossa língua, nossa culinária e muitos de nossos costumes, sua participação foi encoberta por essa tentativa de seguir os padrões eurocêntricos.

Em entrevista recente à Najla Passos, o índio José Humberto Costa do Nascimento, o Tiuré Potiguara, afirma que "houve extermínio sistemático de aldeias indígenas na ditadura". Na mesma entrevista temos ainda o seguinte ponto de vista em forma de proposição:

A sociedade brasileira vem de uma herança colonizadora que já soma 500 anos de exclusão indígena. Até hoje nós não temos nossa história contada por nós mesmos. Há sempre uma história oficial que se sobrepõe. Então, esse reencontro da sociedade branca com a sociedade indígena, a tal reconciliação de que tanto se fala hoje, passa por esse reconhecimento do outro, pela aceitação dos primeiros habitantes desta 
terra, da sua cultura, da sua herança cultural para o povo brasileiro. Infelizmente, ainda não temos esse respeito. (Nascimento, 2012)

Se podemos entender que isso tenha acontecido durante um estado de exceção, dado o seu caráter autoritário, como entender a violência do estado brasileiro contra os povos indígenas durante na vigência do estado democrático de direito? Como entender que o estado contrarie sua própria legislação, negando direitos constitucionais aos povos indígenas?

Ora, parece-nos que a explicação mais razoável é que o estado brasileiro adotou um padrão colonial e racista, seguindo um modelo de desenvolvimento que ignora e atropela formas de vida diferentes da hegemônica. Ao negar a voz às populações indígenas ou ao ignorar seus protestos e clamores o estado brasileiro nega-lhes o direito de cidadania. Mais do que transformá-los em cidadãos de segunda classe, entendemos que o estado brasileiro continua reafirmando o padrão colonial de dominação, ou seja, adota uma forma racista de organização e de estabelecimento de políticas públicas. Sem se tornar completamente ocidental, reproduz o que de pior essa sociedade produziu: um modelo de desenvolvimento carregado de racismo, exclusão e violência.

\section{Referências Bibliográficas}

Advocacia Geral da União (AGU). Portaria nº 303, de 16 de julho de 2012. Disponível em: http://www.agu.gov.br. Acesso em: 11 set. 2012.

Agamben, G. Homo Sacer: o poder soberano e a vida nua I. Belo Horizonte: Ed. UFMG, 2007. 
Arendt, H. Entre o passado e o futuro. 4. ed. São Paulo: Perspectiva, 1997. H. Sobre a violência. 3.ed. Rio de Janeiro: Relume Dumará, 2001.

Baudrillard, Jean. A transparência do mal: ensaio sobre fenômenos extremos. 7. ed. Campinas: Papirus, 1990.

Bauman, Z. Modernidade líquida. Rio de Janeiro: Zahar, 2001.

Brepohl de Magalhães, Marion. Pensamento e ação na obra de Hannah Arendt. História E Perspectivas. Uberlândia, MG, n. 24, 2001.

Cajigas-Rotundo, Juan Camilo. La biocolonialidad del poder. Amazonía, biodiversidad y ecocapitalismo. In: Castro-Gómez, Santiago; Grosfoguel, Ramón (Org.). El giro decolonial: reflexiones para una diversidad epistémica más allá del capitalismo global. Bogotá: Siglo del Hombre Editores; Universidad Central, Instituto de Estudios Sociales Contemporáneos y Pontificia Universidad Javeriana, Instituto Pensar, 2007.

Castro-Gómez, Santiago. La pos-colonialidad explicada a los niños. Popayán - Colombia: Editorial Universidad del Cauca. Instituto Pensar, Universidad Javeriana, 2005.

Dussel, Enrique. 1492: El encubrimiento del outro. Hacia el origen del mito de la modernidad. La Paz: Plural editores, 1994.

Enrique. Meditaciones anti-cartesianas: Sobre el origen del anti-discurso filosófico de la modernidad. Tabula Rasa. Bogotá - Colombia, n. 9, p. 153-197, juliodiciembre 2008.

Farge, Arlette. Violência. In: Burguière, André. Dicionário das ciências históricas. Rio de Janeiro: Imago, 1993.

Gonçalves, Carolina. Comunidade Guarani Kaiowá no MS é novamente atacada a tiros. Carta Capital, 29 de agosto de 2012. In: http://www.cartacapital.com.br/sociedade/comunidade-guarani-kaiowa-no-ms-enovamente-atacada-a-tiros/. Acesso em: 05 set. 2012.

Hardt, Michael; Negri, Antonio. Império. Rio de Janeiro, RJ; São Paulo, SP: Record, 2001. 
Leonardi, Victor Paes de Barros. Entre árvores e esquecimentos: história social nos sertões do Brasil. Brasília: Paralelo 15, 1996.

Nascimento, José Humberto Costa do. "Houve extermínio sistemático de aldeias indígenas na ditadura". Entrevista concedida a Najla Passos. Carta Maior, 2 de agosto de 2012. Disponível em: http://www.cartamaior.com.br/templates/materiaMostrar.cfm?materia_id=20650\&boleti m_id=1309\&componente_id=21449. Acesso em: 12 set. 2012.

Onfray, Michel. A escultura de si. Rio de Janeiro: Rocco, 1995.

Pelbart, Peter Pál. Vida capital: ensaios de biopolítica. São Paulo: Iluminuras, 2003.

Quijano, Anibal. Colonialidade do poder, eurocentrismo e América Latina. In: Lander, Edgardo (Org.). A colonialidade do saber: eurocentrismo e ciências sociais. Perspectivas latino-americanas. Buenos Aires: CLACSO, 2005, p. 227-278. In: http://bibliotecavirtual.clacso.org.ar/, p. 201-246.

Rodó, José Enrique. Ariel. Campinas, SP: Editora da UNICAMP, 1991. 